\title{
Desulfurization of Dibenzothiophene from Model Oil by Aluminum Ammonium Sulfate/Urea (Alum) Ionic Liquid Analogue
}

\author{
Noor Emad Faseh, Hadi M. A. Abood*
}

Department of Chemistry, College of Science, Al-Nahrain University, Baghdad, Iraq

\begin{tabular}{|c|c|}
\hline Articles Information & Abstract \\
\hline $\begin{array}{l}\text { Received: } \\
\text { 04.02.2020 } \\
\text { Accepted: } \\
\text { 18.02.2020 } \\
\text { Published: } \\
\text { 04.06.2020 }\end{array}$ & $\begin{array}{l}\text { Petroleum is the most important source of energy which is required to be free of } \\
\text { sulfur. Ionic liquid analogue was used to desulfurize Model oil at several } \\
\text { conditions including different concentration of dibenzothiophene (DBT), time of } \\
\text { extraction, temperature and ionic liquid analogue to Model volume ratios. The } \\
\text { cheap and easy made ionic liquid analogue is a mixture of } 1: 5 \text { mole ratio of } \\
\text { Aluminum ammonium sulfate. } 12 \mathrm{H} 2 \mathrm{O} \text { : Urea (Alum). The desulfurization was } \\
\text { followed by ATR-IR GC-MS Aluminum salt ionic liauid analogue was found to }\end{array}$ \\
\hline $\begin{array}{l}\text { Keywords: } \\
\text { Ionic liquid } \\
\text { Deep eutectic solvent } \\
\text { Desulfurization Dibenzothiophene } \\
\text { Ammonium Sulfate } \\
\text { Urea }\end{array}$ & $\begin{array}{l}\text { have more than } 90 \% \text { removal of DBT from its mixture with decane (Model). The } \\
\text { process in the Alum solvent was attributed to combination of an absorption and } \\
\text { possibly oxidation of DBT through interaction of sulfur with the oxygen of } \\
\text { sulfate group of the ionic liquid analogue when the IR bands of sulfate and } \\
\text { hydrogen bond of ionic liquid analogue were influenced strongly by this } \\
\text { interaction. The removal of dibenothiophene was more effective at } 30^{\circ} \mathrm{C} \text { and } 10 \\
\text { min than higher temperature and longer time. }\end{array}$ \\
\hline
\end{tabular}

DOI: $10.22401 /$ ANJS.23.2.02

* Corresponding author: drha85@yahoo.co.uk

\section{Introduction}

Petroleum is the most important source of energy for the world, it is a mixture of large number of hydrocarbon compounds, besides carbon and hydrogen it contains many elements in different proportions such as sulfur(0.02-8\%), nitrogen $\left(0.1^{-}\right.$ $2 \%$ ), oxygen(0.05-1.5\%) with small quantities of metallic constituents such as vanadium, nickel [14]. Sulfur containing some compounds in fuel oil, such as thiophenes (T), benzothiophenes (BT), and dibenzothiophenes (DBT), produce sulfur oxides (SOx) upon combustion, which are responsible for acid rain pollution which also inhibit the catalyst during the desulfurization "DES" process of fuel oil in refining industries $[5,6]$. The removal of sulfur from transportation fuel is gaining attention due to the increased awareness of the adverse effects of burning sulfur containing oils on human health and the environment. Hence, desulfurization of fuel oils has become a critical component of the oil refining industries [7]. Therefore, removal of such sulfur-containing compounds is important for the production of green fuel oils to meet the new standards of sulfur content(10-15 ppm) as per the recommendations of the United State Protection Agency (USEPA), given the environmental concerns surrounding sulfur[8-11].
Many methods have been developed or innovated for used to remove sulfur compounds from crude oil and many studies have been developed for the purpose of development of these techniques [1216].Sulfur removal techniques depending on how the compound is removed, such as catalytic hydrodesulphurization (HDS). Simplicity of the DES process, extraction-desulphurization, has been widely researched mainly due to the low energy consumption, lower temperature and pressure operating conditions as compared to HDS[17]. Ionic liquids (ILs) have been for the two decades researched as a solvent for extractiondesulphurization. ILs are majorly formed from one type of discrete anion or cation held together via ionic bonding which contributes to very low vapor pressure with melting points less than $100^{\circ} \mathrm{C}$. The possibility of tailoring the properties of ILs by altering the combination of the cations and anions as well as the non-volatility portrayed made ILs a good candidate to replace the conventional volatile organic solvents [18-20]. However, recent studies have raised concerns about the toxicity and poor biodegradability of ILs towards environmental damage [21-24]. Deep eutectic solvents are analogues to ILs that have attracted great attention because of their excellent physical properties which can be easily tuned for specific 


\title{
Al-Nahrain Journal of Science
}

\author{
ANJS, Vol.23 (2), June, 2020, pp. 8 - 17
}

uses. DESs consist of a mixture of two or more compounds having hydrogen-bond donors (HBD) and hydrogen- bond acceptors(HBA) that form a eutectic mixture [25]. Selection of suitable DESs is important as it affects the extraction efficiency. Triethylamine(TEtA) and organic acids have extraction efficiency around 50\%. Some DESs are made from choline chloride, tetramethyl ammonium chloride, and TBAC as $\mathrm{HBA}$ and malonic acid, glycerol, tetra ethylene glycerol, ethylene glycol, polyethylene glycol, and propionate(Pr) as HBD [26-27]. The novel hydrated ammonium alum/urea a DESs or Ionic liquid analogue with reasonable thermal stability [28,29] was chosen for the first time for desulfurization as it also possess several distinct properties, including its immiscibility with fuel (non-polar decane) due to consisting of water molecules in its structure and having sulfate oxy-anion which expected to facilitates the separation process, as well as low cost and ease of preparation. Several important desulphurization conditions such as DES to Model ratio, temperatures and time of extraction and DBT concentration will be studied and to be followed by ATR-IR and GC-MS.

\section{Experimental}

Chemical Reagents: All the chemicals which used in this work were of the highest purity available and supplied without further purification. Decane (99\%) of BDH, Dibenzothiophene (97\%) of RiedelDe haen, Ammonium aluminum Sulfate.12-Hydrat (99\%) of Merck, Urea (99.5\%) of FLUKA. Synthesis of Alum Ionic Liquid analogue: Ionic liquid analogue was prepared by mixing 1:5 mol ratio of Ammonium alum : urea respectively and mixed and heated at $75-85{ }^{\circ} \mathrm{C}$ for $3 \mathrm{hrs}$ with continues stirring, giving a colorless liquid when left to cool at room temperature [28,29]. Preparation of models: The models were prepared by dissolving certain weight of powder dibenzothiophene in a proper volume of decane, forming colorless liquid Models of required concentrations, for example a Model of $500 \mathrm{ppm}$ prepared by dissolving $12.5 \mathrm{mg}$ dibenzothiophene in $25 \mathrm{ml}$ of decade.

\section{Desulfurization process:}

The desulfurization process was carried out by mixing and mechanical stirring a proper volume of ionic liquid analogue with the model, then the mixture was heated to a temperature not exceeding $70^{\circ} \mathrm{C}$ or 3 hours. The heated mixtures were finally left to cool at room temperature.

\section{Result and Discussion}

Desulfurization of Model containing 500 ppm DBT at different Model:DES volume ratios: After the desulfurization, the final mixture was separated into two layers, the top hydrocarbon (decane) layer was clear transparent while the bottom layer changed from transparent before desulfurization to opaque layer. The volume ratios of Models containing 500 ppm DBT to ionic liquid analogue were $1: 5,2: 5$ and $3: 5$, heated to $30^{\circ} \mathrm{C}$ for $10 \mathrm{~min}$.. Samples from the both layers were analyzed by ATR-IR and GC-MS as follows:

\section{ATR-IR for the top hydrocarbon layer (decane layer) $30^{\circ} \mathrm{C}$ and $10 \mathrm{~min}$ :}

The main bands for all samples of ATR-IR are represented in Table (1), while the IR spectrum of decane alone in Figure 1-A, DBT alone in Figure $1-\mathrm{B}$, decane containing $500 \mathrm{ppm}$ DBT (Model) in Figure1-C, Model after desulfurization with 1:5 volume ratio in Figure 4, Model after desulfurization with 1:5, 2:5 and 3:5 volume ratio in Figure $2(\mathrm{~B}, \mathrm{C}, \mathrm{D})$ respectively. The main bands for DBT and decane in pure material and in model before and after desulfurization indicated the vibrational bands of $\mathrm{C}-\mathrm{H}$ (aliphatic) of decane at $2956 \mathrm{~cm}^{-1}$ and DBT(aromatic) at $3050 \mathrm{~cm}^{-1}$, while $\mathrm{C}=\mathrm{C}$ of $\mathrm{DBT}$ at $1062 \mathrm{~cm}-1$. The most important band is the C-S band which is at $735 \mathrm{~cm}^{-1}$ in DBT which is taken as a representative band for the presence of DBT in the model. Hence it is found that this band has disappeared from the Model after desulfurization at volume ratios of eutectic solvent to model of (1:5, 2:5 and 3:5 respectively) see Fig.2. This was taken as an evidence for removal of DBT from the Model for shorter time of 10 minutes at $30^{\circ} \mathrm{C}$, compare Figure 2-A with Figure 2-C,D,E. where the model retain the vibrational bands of pure decane after desulfurization. 


\section{Al-Nahrain Journal of Science}

ANJS, Vol.23 (2), June, 2020, pp. 8 - 17

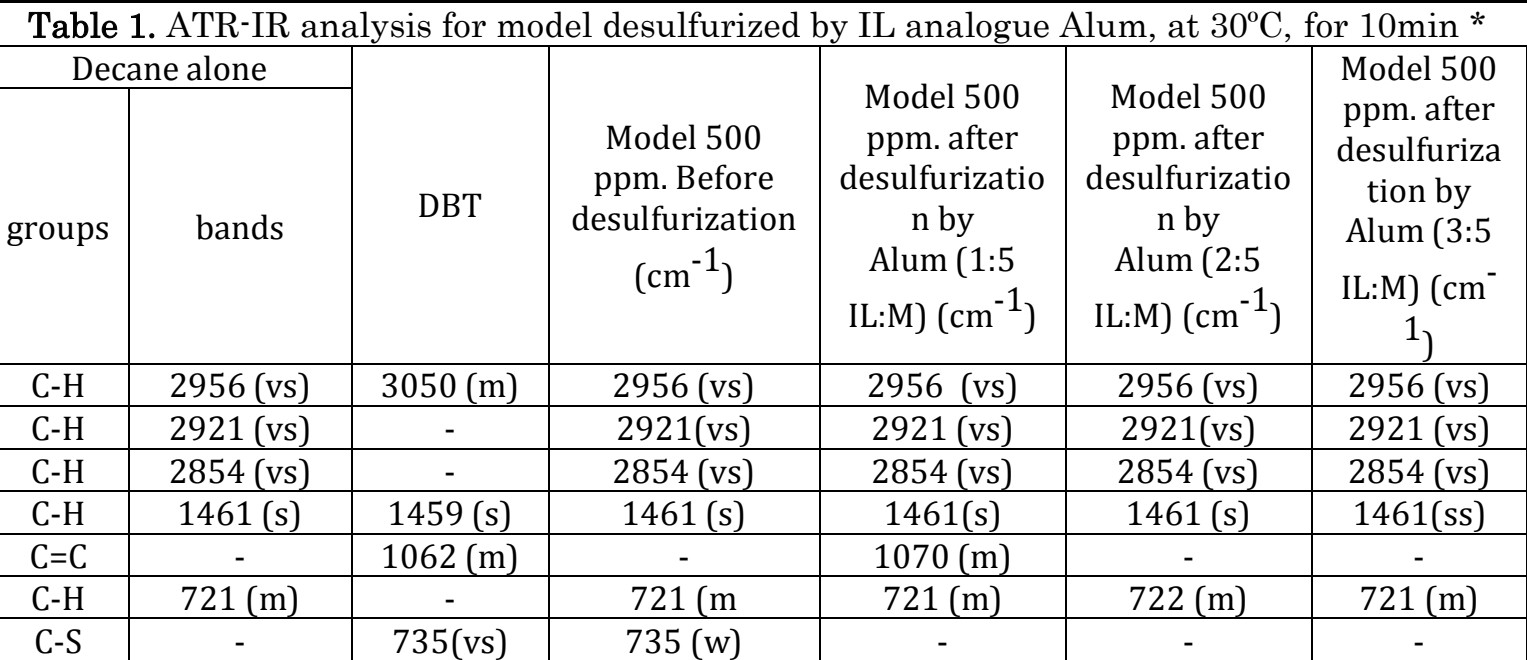

* vs:very strong, s:strong, m:medium, w:weak

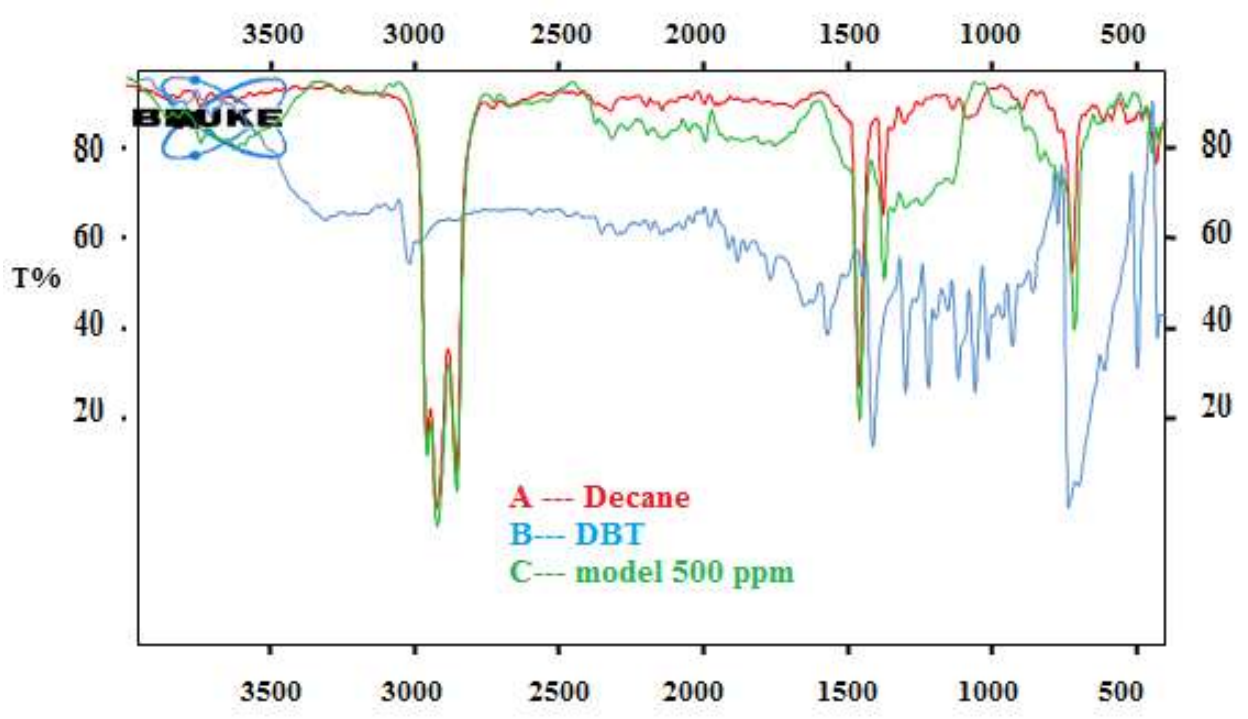

Figure 1. ATR-IR of (A) Decane only (B) DBT alone and (C) Model containing 500 ppm DBT

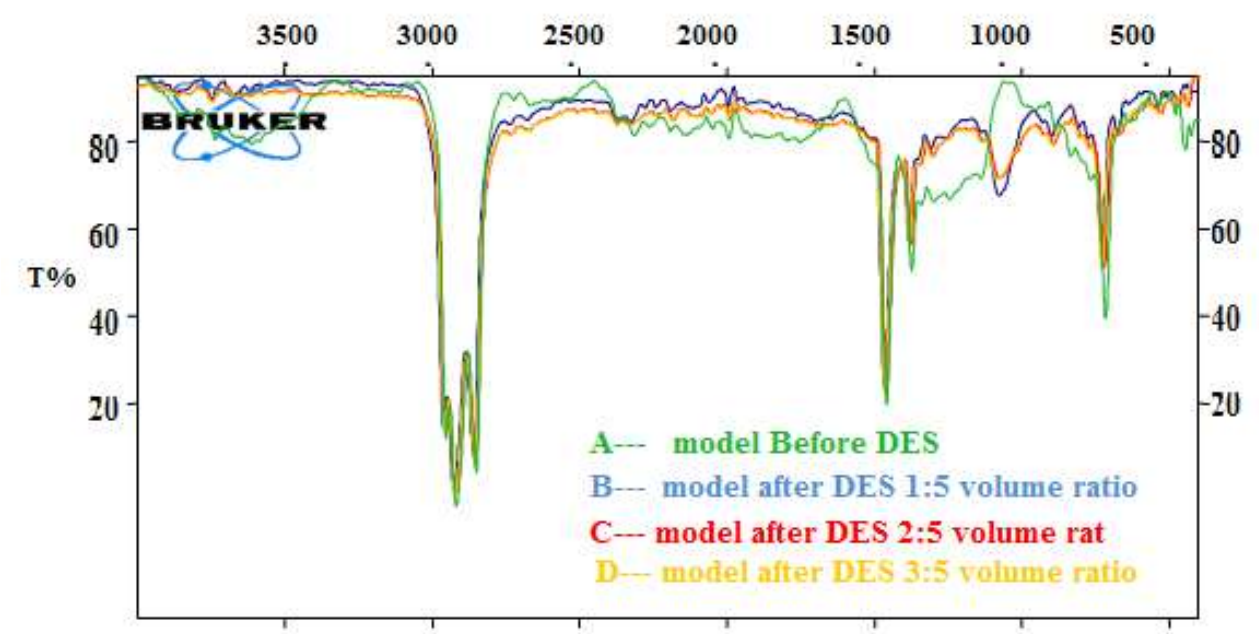

Figure 2. ATR-IR of (A) Model containing 500 ppm DBT before DES (B) model after DES 1:5 volume ratio (B) Model after DES 2:5 volume ratio (C) Model after DES 3:5 volume ratio, at $30^{\circ} \mathrm{C}$ for $10 \mathrm{~min}$. 


\title{
Al-Nahrain Journal of Science
}

\author{
ANJS, Vol.23 (2), June, 2020, pp. 8 - 17
}

\begin{abstract}
ATR-IR of the bottom layer of the eutectic solvent:
IL analogue alone (Figure 3- A) showed the main bands of the hydrogen bond appears as a broad band from around $2500 \mathrm{~cm}^{-1} 1$ to $3600 \mathrm{~cm}^{-1}$ which is related to both intra hydrogen bond resulted from the hydrogen bonds of the water molecules in Aluminum ammonium sulfate. 12 hydrate and the hydrogen bond resulted from the interaction of the hydrogen of water crystal structure of Alum with oxygen of sulfate. Hydrogen bond of the DES showed broad band too with a top band at 3200 $\mathrm{cm}^{-1}, 3342 \mathrm{~cm}^{-1}$ and $3457 \mathrm{~cm}^{-1}$ [ 30,31]. Other bands at lower frequencies are of bending $\mathrm{N}-\mathrm{H}, \mathrm{C}=\mathrm{O}$ and $\mathrm{C}-\mathrm{N}$ vibration at $1631 \mathrm{~cm}^{-1}, 1579 \mathrm{~cm}^{-1}$ and $1458 \mathrm{~cm}^{-1}$ respectively. At lower frequency the sulfate vibration band appeared as broad band centered at $1054 \mathrm{~cm}^{-1}$. IL analogue after desulfurization (Figure 3: B-C-D) showed major changes in its vibrational frequencies as showed in Fig. 3 that are summarized in Table 2. The major changes appeared at the sulfate band which although it centered at the close vibrational frequency of 1058 $\mathrm{cm}^{-1}$ to that before desulfurization $\left(1062 \mathrm{~cm}^{-1}\right)$ but it showed many shoulder peaks on its low and higher side frequency with broader shape than it was in the IL analogue before desulfurization. In addition, the broad hydrogen bond band at 2500 $\mathrm{cm}^{-1}$ to $3600 \mathrm{~cm}^{-1}$ in IL analogue alone showed a separated bands at $3344 \mathrm{~cm}^{-1}$ and $3457 \mathrm{~cm}^{-1}$ which may be attributed to $\mathrm{NH} 2$ vibration bands near a broad band at $2500 \mathrm{~cm}^{-1}$ to $3100 \mathrm{~cm}^{-1}$ of the hydrogen bonds and an $\mathrm{O}-\mathrm{H}$ at $3736 \mathrm{~cm}^{-1}$ of water. [31,32]. . It may be worth indicating that the $\mathrm{N}-\mathrm{H}$, $\mathrm{C}=\mathrm{O}, \mathrm{C}-\mathrm{N}$ and the back bone of the Alum alone remain nearly unchanged after extraction,
\end{abstract}

band at $2837 \mathrm{~cm}^{-1}$ related to $\mathrm{C}-\mathrm{H}$ vibration indicating the presence of DBT. These vibration changes indicated that the DBT was successfully removed from the model due to interacted with the Alum probably at the oxygen of the sulfate (i.e. DBT-S---OS) thereby broaden the sulfate vibrational band with many shoulders. This interaction would weaken the sulfate interaction which originally hydrogen bond was broken and the amine and water groups were released from the interaction with the sulfate to show a separate bands at higher frequencies of $3344 \mathrm{~cm}^{-1}$ and $3457 \mathrm{~cm}^{-1} 1$ for amines group and $3736 \mathrm{~cm}^{-1}$ for water molecule. This is in agreement to a suggested mechanism of extracting sulfur by DES in which hydrogen bond is highlighted as a major factor which influences the DES[26, 33- 35]. This was said to arise from the aromatic structure of DBT is weakened by the strong interaction between deep eutectic solvents and DBT thus susceptible to oxidation. Secondly, there is $\Pi^{-}$ complexation between sulphur atoms and metal ions thereby DBT is oxidized to DBTO2 (sulfones).

\section{The effect of changing reaction conditions :}

Lower concentration of $100 \mathrm{ppm}$ of the Model was taken to evaluate the efficiency of the DES to desulfurize the model at $70{ }^{\circ} \mathrm{C}$ as many workers carried out their process at around $70{ }^{\circ} \mathrm{C}$ which might enhance a reaction between DBT with the oxygen of the sulfate producing sulfoxide [26,36]. Model volume ratio at $70^{\circ} \mathrm{C}$ for 1 hour is presented in Figure 4 (B), while the main vibrational group are presented in Table (3), it is shown that the vibrational frequency of the hydrogen bond at 2500 $\mathrm{cm}^{-1}$ to $2600 \mathrm{~cm}^{-1}$ was not effected while bands around $2800 \mathrm{~cm}-1$ referred to $\mathrm{C}-\mathrm{H}$ frequency and small broadening of the sulfate band centered at $1058 \mathrm{~cm}^{-1}$ was also recorded. This was attributed to little interaction between DBT and the IL solvent. To evaluate the time effect, this experiment was carried out for $2 \mathrm{hrs}$ and $3 \mathrm{hrs}$ respectively. The ATR-IR of both experiments are presented in Figure 4(C) and (D) respectively, while their main vibrational bands are shown in Table (3). After $2 \mathrm{hrs}$ the results were similar to those obtained previously at $10 \mathrm{~min}$. and $30 \mathrm{C}$ as the sulfate band was broadened with several shoulders and the appearance of separated bands of $\mathrm{N}-\mathrm{H}$ and $\mathrm{OH}$. This changes indicated a much better extraction of DBT at $70^{\circ} \mathrm{C}$ for $2 \mathrm{hrs}$ than the $1 \mathrm{hr}$.These are in contrast to other reports that indicate lower extraction of sulfur at high temperature and or time [26, 27,37- 39]. This might be related to inhibition of the exothermic reaction related to acid-base complexation suggested at high temperature [40]. This contrast between reported and present work could be related to the DES used in this work that have sulfate ions which could provide enhanced interaction with the sulfur benzene rings. However, the ATR-IR after the desulfurization for $3 \mathrm{hrs}$ at $70^{\circ} \mathrm{C}$ Figure 4 (D) indicate the Alum DES to have no changes in its frequencies as they retained that of IL analogue before desulfurization. This was attributed to the time effect as it exceeded the threshold of optimum desulfurization and attributed to evaporation of the desulfurized DBT from IL solvent. 


\title{
Al-Nahrain Journal of Science
}

\author{
ANJS, Vol.23 (2), June, 2020, pp. $8-17$
}

Table 2. ATR-IR vibration bands of Alum IL before and after desulfurization of model containing 500ppm $\mathrm{DBT}^{*}$. *s: very strong, s:strong, m:medium, w:weak

Group of ionic liquid alone before

Ionic liquid after desulfurization, at $30^{\circ} \mathrm{C}, 10 \mathrm{~min}$.

\begin{tabular}{|c|c|c|c|c|}
\hline Group & Band & $\begin{array}{c}\text { Ratio 1:5 (IL:M) } \\
\mathrm{cm}^{-1}\end{array}$ & $\begin{array}{c}\text { Ratio } 2: 5 \text { (IL:M) } \\
\mathrm{cm}^{-1}\end{array}$ & $\begin{array}{c}\text { Ratio } 4: 5 \text { (IL:M) } \\
\mathrm{cm}^{-1}\end{array}$ \\
\hline $\mathrm{O}-\mathrm{H}\left(\mathrm{H}_{2} \mathrm{O}\right)$ & - & $3736(\mathrm{~m})$ & $3736(\mathrm{~m})$ & $3736(\mathrm{~m})$ \\
\hline $\mathrm{N}-\mathrm{H}$ & - & $3674(\mathrm{~m})$ & $3674(\mathrm{~m})$ & $3674(\mathrm{~m})$ \\
\hline $\mathrm{N}-\mathrm{H}$ & & $3459(\mathrm{~m})$ & $3457(\mathrm{~m})$ & $3344(\mathrm{~m})$ \\
\hline $\mathrm{N}-\mathrm{H}$ & 3342 (vs) & 3347 (m) & $3344(\mathrm{~m})$ & 3345 (m) \\
\hline $\mathrm{N}-\mathrm{H}$ & 3200 (vs) & $3200(\mathrm{~S})$ & $3200(\mathrm{~s})$ & $3200(\mathrm{~s})$ \\
\hline $\mathrm{N}-\mathrm{H}$ & $3100(\mathrm{~s})$ & $3100(\mathrm{~s})$ & $3100(\mathrm{~s})$ & $3100(\mathrm{~s})$ \\
\hline $\mathrm{C}-\mathrm{H}$ of decane & & $2850(\mathrm{~s})$ & $2837(\mathrm{~s})$ & $2829(\mathrm{~s})$ \\
\hline $\mathrm{N}-\mathrm{H}$ & 1623 (vs) & 1631 (vs) & 1629 (vs) & 1630 (vs) \\
\hline $\mathrm{C}=\mathrm{O}$ & 1579 (vs) & 1581 (vs) & 1580 (vs) & 1580 (vs) \\
\hline $\mathrm{C}-\mathrm{N}$ & 1458 (vs) & 1461 (vs) & 1463 (vs) & 1461 (vs) \\
\hline $\mathrm{SO} 4$ & $1054(\mathrm{vs})$ & 1056 (vs) & 1058 (vs) & 1058 (vs) \\
\hline C-S from DBT & & $738(\mathrm{w})$ & $738(\mathrm{w})$ & $738(\mathrm{w})$ \\
\hline Urea back bone & $603(\mathrm{~m})$ & $608(\mathrm{~m})$ & $610(\mathrm{~m})$ & $610(\mathrm{~m})$ \\
\hline Urea back bone & $523(\mathrm{~m})$ & $532(\mathrm{~m})$ & $530(\mathrm{~m})$ & $537(\mathrm{~m})$ \\
\hline
\end{tabular}

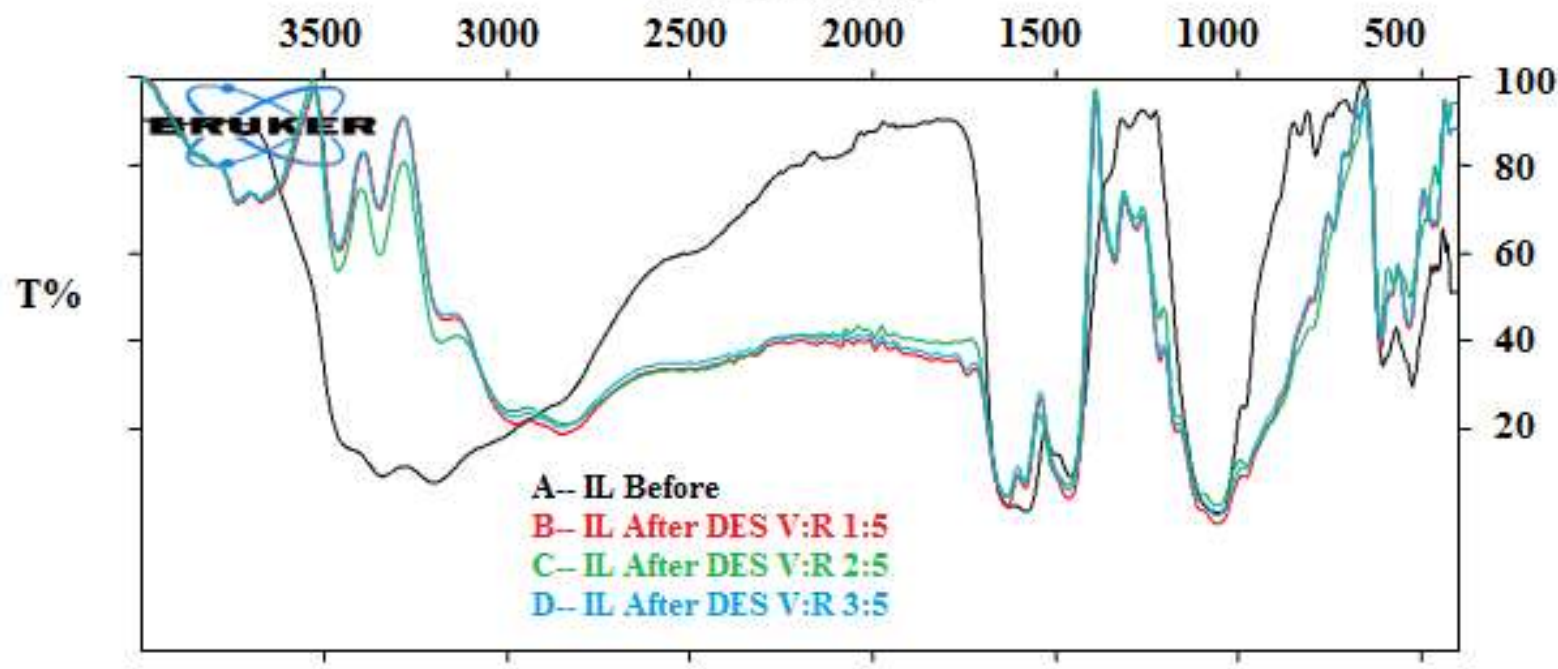

Figure 3. ATR-IR for (A) IL before DES (B) IL after DES Volume ratio 1:5 (C) IL after DES Volume ratio 2:5 (D) IL after DES Volume ratio 3:5. 


\section{Al-Nahrain Journal of Science}

ANJS, Vol.23 (2), June, 2020, pp. $8-17$

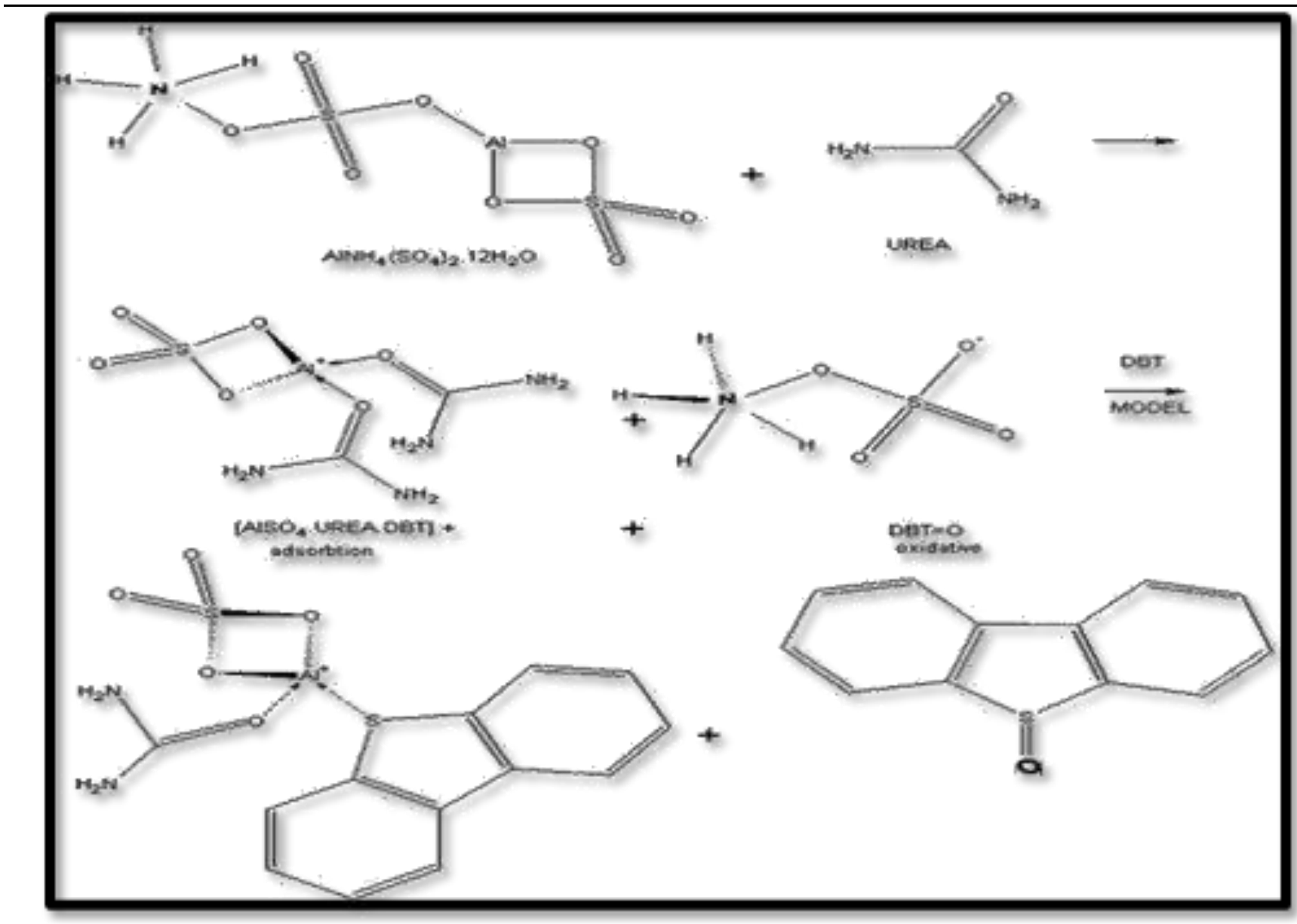

Scheme 1. Mechanisum of DBT oxidation

Table 3. ATR-IR vibrational bands of DESs at different desulfurization conditions. * *vs:very strong, s:strong, m:medium, w:weak

\begin{tabular}{|c|c|c|c|c|}
\hline \multicolumn{2}{|c|}{$\begin{array}{c}\text { Group of alone Ionic liquid before } \\
\text { desulfurization }\left(\mathrm{cm}^{-1}\right)\end{array}$} & \multicolumn{3}{|c|}{$\begin{array}{l}\text { Ionic liquid after desulfurization at } 70^{\circ} \mathrm{C}, 3: 5 \text { (IL:Model) volume } \\
\text { mole ratio }\left(\mathrm{cm}^{-1}\right)\end{array}$} \\
\hline groups & bands & Time: 1 hour & Time: 2 hours & Time: 3 hours \\
\hline $\mathrm{O}-\mathrm{H}$ (water) & - & _- & $3736(\mathrm{~m})$ & - \\
\hline $\mathrm{N}-\mathrm{H}$ & - & - & $3675(\mathrm{~m})$ & - \\
\hline $\mathrm{N}-\mathrm{H}$ & - & & $3464(\mathrm{~m})$ & - \\
\hline $\mathrm{N}-\mathrm{H}$ & $334 \overline{2}$ (vs) & $334 \overline{2}$ (vs) & 3346 (vs) & $334 \overline{3}$ (vs) \\
\hline $\mathrm{N}-\mathrm{H}$ & 3200 (vs) & $3200(\mathrm{~s})$ & J & $3198(\mathrm{~s})$ \\
\hline $\mathrm{N}-\mathrm{H}$ & $3100(\mathrm{~s})$ & $3100(\mathrm{~s})$ & $3100(\mathrm{~s})$ & $3100(\mathrm{~s})$ \\
\hline $\mathrm{N}-\mathrm{H}_{2}$ & $1623(\mathrm{~s})$ & $1626(\mathrm{~s})$ & $1637(\mathrm{~s})$ & $1635(\mathrm{~s})$ \\
\hline $\mathrm{C}=\mathrm{O}$ & $1579(\mathrm{~s})$ & $1579(\mathrm{~s})$ & $1572(\mathrm{~s})$ & $1584(\mathrm{~s})$ \\
\hline $\mathrm{C}-\mathrm{N}$ & $1458(\mathrm{~s})$ & $1458(\mathrm{~s})$ & $1475(\mathrm{~s})$ & 1449 (s) \\
\hline $\mathrm{SO}_{4}$ & $1054(\mathrm{~s})$ & $1058(\mathrm{~s})$ & 1062 (s) & 1057 (s) \\
\hline \multirow[t]{2}{*}{ C-S } & & $734(w)$ & $737(\mathrm{~m})$ & \\
\hline & $603^{-}(\mathrm{m})$ & $601(\mathrm{~m})$ & $608(\mathrm{~m})$ & $601^{-}(\mathrm{m})$ \\
\hline Urea back bone & $523(\mathrm{~m})$ & $530(\mathrm{~m})$ & $541(\mathrm{~m})$ & $529(\mathrm{~m})$ \\
\hline
\end{tabular}




\section{Al-Nahrain Journal of Science}

ANJS, Vol.23 (2), June, 2020, pp. 8 - 17

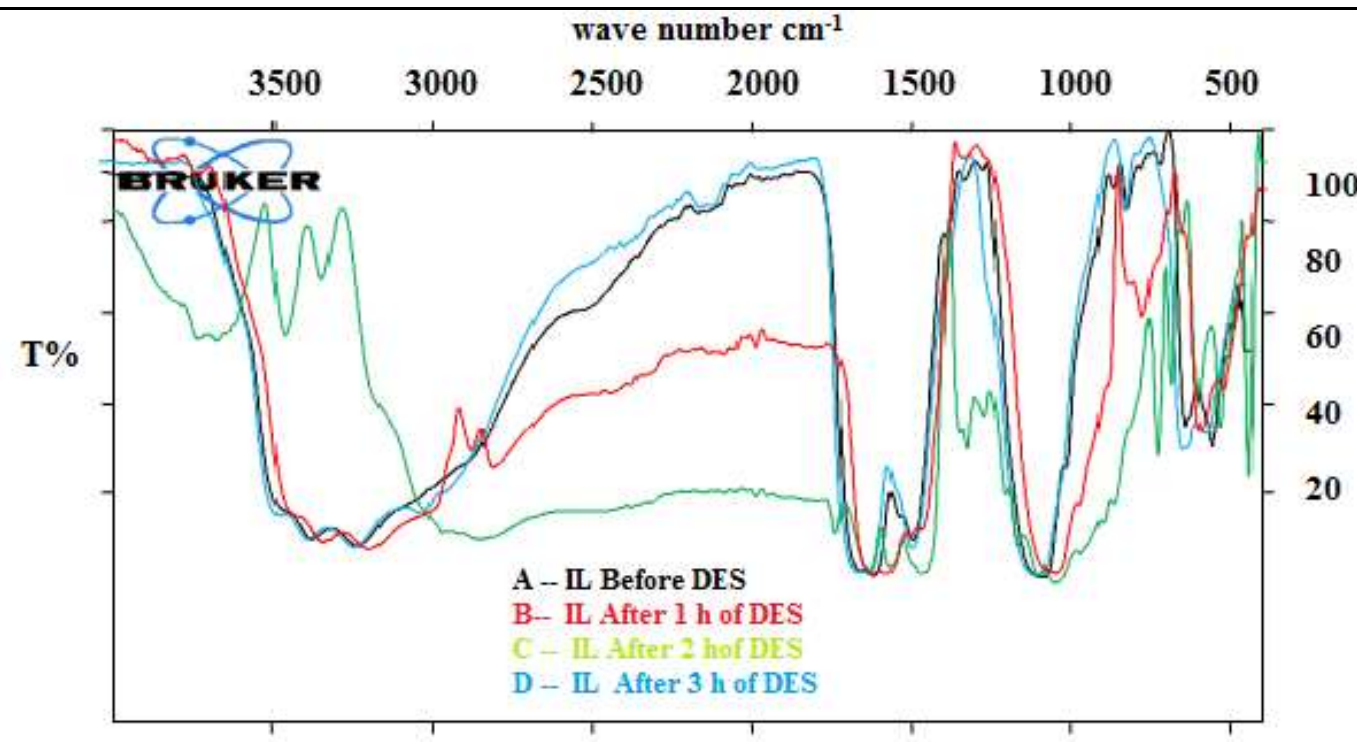

Figure 4. ATR-IR of (A)deep eutectic solvent after DES of model containing $100 \mathrm{pm}$ at $70^{\circ} \mathrm{C}$, volume ratio 3:5, for (B) $1 \mathrm{hr}$ (C) $2 \mathrm{hrs}$ (D) $3 \mathrm{hrs}$

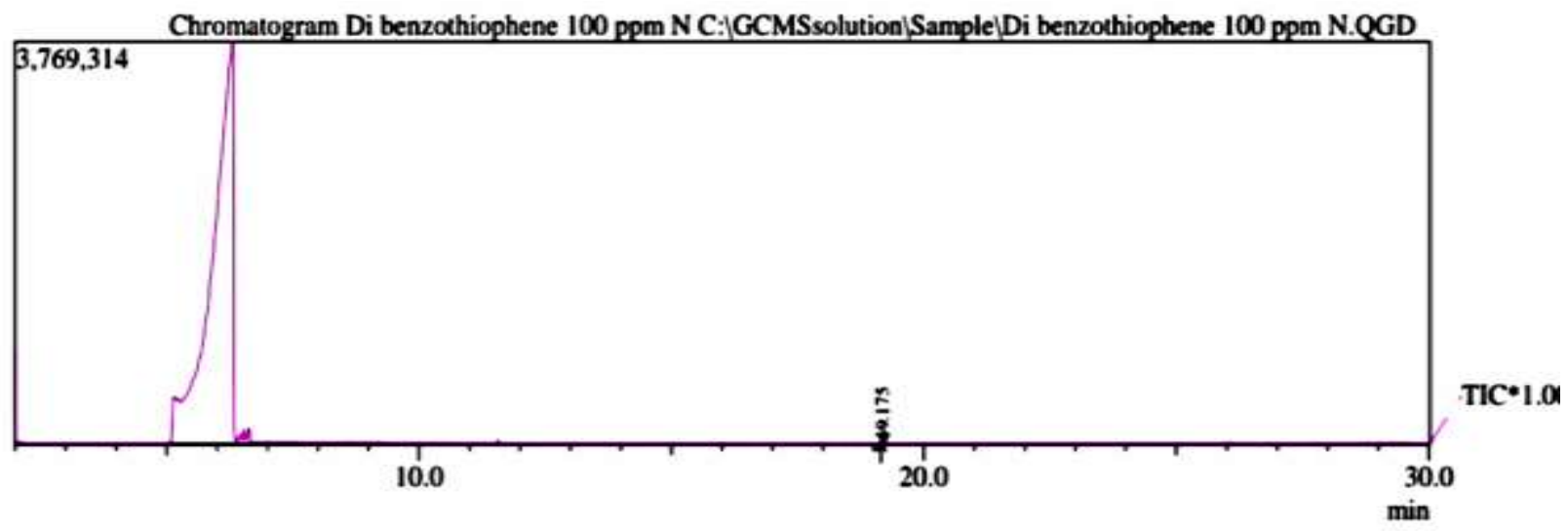

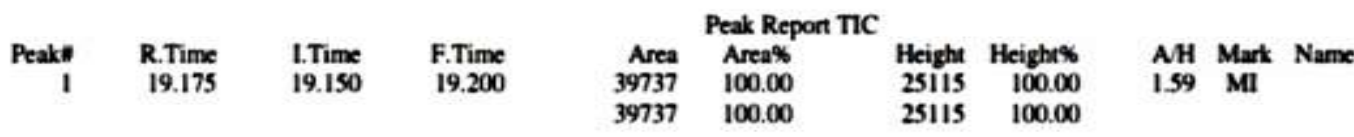

Figure 5. GC-Ms for model 100 ppm before desulfurization

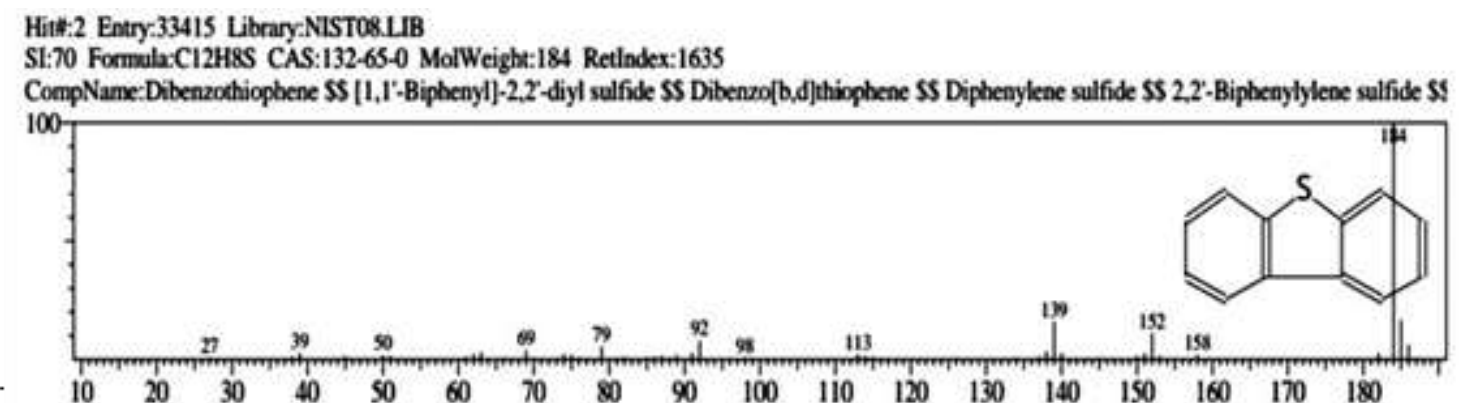

Figure 6. GC-MS for DBT. 


\section{Al-Nahrain Journal of Science}

ANJS, Vol.23 (2), June, 2020, pp. 8 - 17

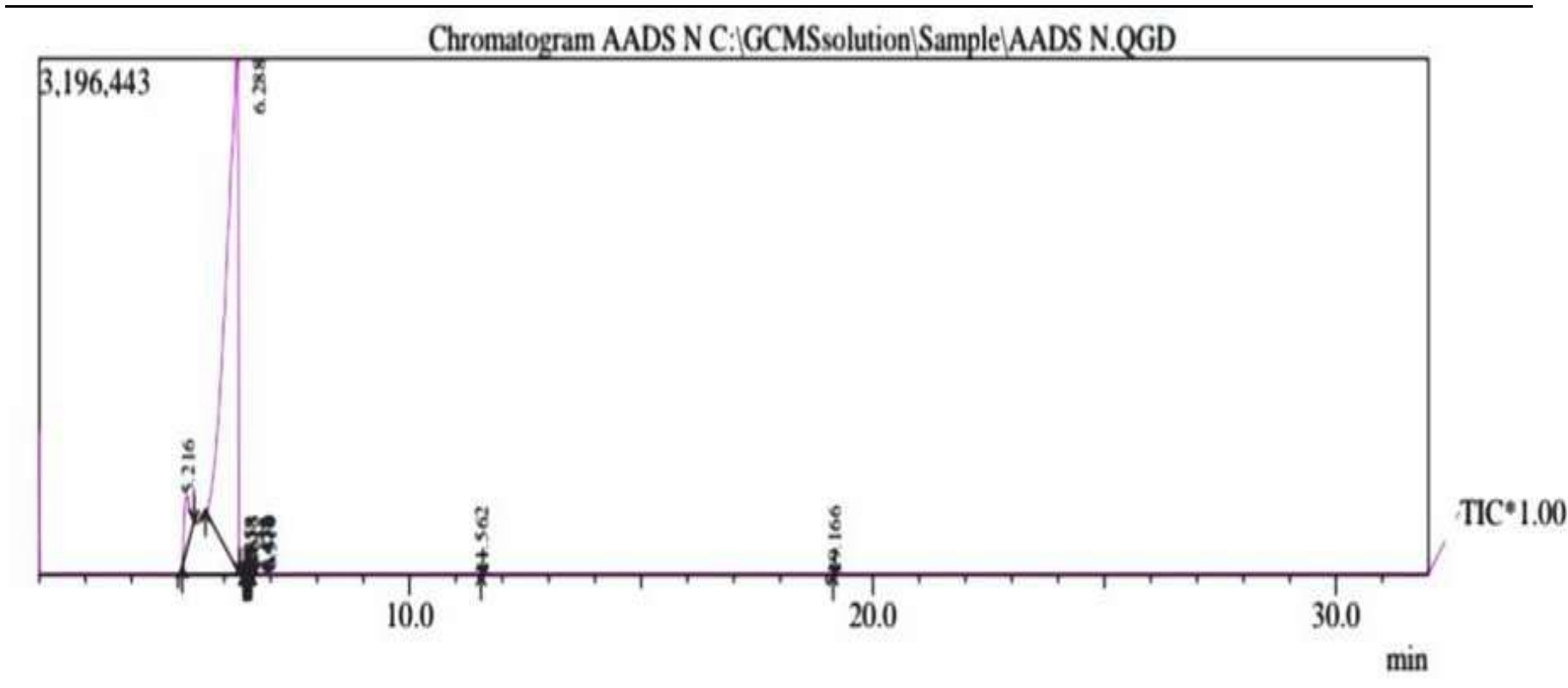

$\begin{array}{rrrrrrrrrr}\text { Peak\# } & \text { R.Time } & \text { I.Time } & \text { F.Time } & \text { Area } & \text { Area\% } & \text { Height } & \text { Height\% } & \text { AH } & \text { Mark Name } \\ 1 & 5.216 & 5.092 & 5.350 & 2955564 & 4.97 & 304089 & 8.63 & 8.40 & \text { MI } \\ 2 & 6.288 & 5.592 & 6.333 & 56390869 & 94.90 & 3169051 & 89.90 & 17.80 & \text { MI } \\ 3 & 6.438 & 6.417 & 6.450 & 6495 & 0.01 & 5369 & 0.15 & 1.14 & \text { MI } \\ 4 & 6.472 & 6.458 & 6.492 & 4160 & 0.01 & 3752 & 0.11 & 1.11 & \text { MI } \\ 5 & 6.519 & 6.500 & 6.533 & 16328 & 0.03 & 13671 & 0.39 & 1.13 & \text { MI } \\ 6 & 6.558 & 6.542 & 6.575 & 5771 & 0.01 & 5092 & 0.14 & 1.13 & \text { MI } \\ 7 & 6.613 & 6.583 & 6.650 & 33791 & 0.06 & 19819 & 0.56 & 1.71 & \text { MI } \\ 8 & 11.562 & 11.542 & 11.583 & 3812 & 0.01 & 2765 & 0.08 & 1.38 & \text { MI } \\ 9 & 19.166 & 19.142 & 19.183 & 2804 & 0.00 & 1607 & 0.05 & 1.74 & \text { MI }\end{array}$

Figure7. GC-MS for model 100 ppm after desulfurization by Alum deep eutectic solvent at $70^{\circ} \mathrm{C}$, for $1 \mathrm{~h}$.

\section{GC-MS analysis:}

The GC-MS analysis was carried out for the model containing $100 \mathrm{ppm}$ DBT in deccane before and after desulfurization at $70^{\circ} \mathrm{C}$ for $1 \mathrm{hr}$ and for the model as illustrated below. The model containing 100ppm befor desulfurization. Figure 5 showed a retention time of RT 19.175 min with $100 \%$ area which is related to DBT. This gave the MS analysis with a molecule weight of 184 and a formula of DBT as shown in Figure 6. The model containing 100 ppm after desulfurization. The GC-MS analysis for the model containing $100 \mathrm{ppm}$ DBT after desulfurization with Alum deep eutectic solvent at 3:5 volume ratio of IL solvent: model containing $100 \mathrm{ppm} \mathrm{DBT}$ at $70^{\circ} \mathrm{C}$ for $1 \mathrm{hr}$ is shown in Figure 7. This Figure contain several retention times which are related to $\mathrm{n}-$ decane (RT 6.288 with
94.90\% area) and tri methyl decane (RT 5.216 with $4.97 \%$ area) both resulted in $99.87 \%$ area. The remaining $0.13 \%$ area could resulted from cracking of some DBT to several cyclic or aliphatic compounds with RT from 6.438 to 6.613 . However, RT 11.562 could be related to pentaedione while $\mathrm{RT}$ of 19.166 with molecule weight of 184 is similar to DBT. It may be deduced from the GC analysis that DBT was either completely removed from the model after desulfurization by Alum deep eutectic solvent or at least was removed by $92.94 \%$ if the RT 19.66 of $0.0075 \%$ area to be DBT of 184 molecular weight. It was suggest that the $92.94 \%$ removal is more realistic conclusion. This is in agreement with the ATR-IR result of Figure 4 which showed an interaction of DBT with the sulfate group. 


\title{
Al-Nahrain Journal of Science
}

\author{
ANJS, Vol.23 (2), June, 2020, pp. 8 - 17
}

\section{Conclusions}

The desulfurization extraction of dibenzothiophene by ionic liquid analogue(DES) of Aluminum Ammonium sulfate.12H2O:urea (1:5) mole was successful . the extraction performed at low temperature of $30^{\circ} \mathrm{C}$ and short time (10min) is more effective than increasing temperature to $70^{\circ} \mathrm{C}$ and time to $3 \mathrm{hrs}$ which showed reversible process as the extracted DBT was cracked forming probability sulfoxide compounds. The extraction of DBT was more than 90\% supporting the compatible efficiency with other ionic liquids. In addition it is the first time that extraction by possible oxidation extraction of DBT. The cheaper ease of formation, handling an safe properties of present solvent has additional advantages over other ionic liquids.

\section{References}

[1] Lobodin, V. V.; Robbins, W. K. J.; Rodgers, R. P.; "Separation and Characterization of Reactive and Non-Reactive Sulfur in Petroleum and Its Fractions"; Ene. Fuel. 29, 6177-6186, 2015.

[2] Dharaskar, S. A.; Deshmukh, S. K.; Bhuyar, K. D.; Wasewar, K. L.; "Effect of the BMIM BF4 immobilization on oxidized activated carbon in fuel desulfurization"; Green Chem. 11, 1-6, 2015.

[3] Faridbod, F.; Rashedi, H.; Ganjali, M. R.; Norouzi P.; Riahi, S.; "Application of room temperature ionic liquids in electrochemical sensors and biosensors"; INTECH, 644-658, 2011.

[4] Wishart, J. F.; "Energy applications of ionic liquids”; Ene. Environ. Sci. 2, 956, 2009.

[5] González-García, O.; Cedeño-Caero, L.; "V-Mo based catalysts for oxidative desulfurization of diesel fuel"; Catal. Today 148, 42-48, 2009.

[6] Rezvani, M. A.; Shaterian, M.; Akbarzadeh, F.; Khandan, S.; "Deep oxidative desulfurization of gasoline induced by $\mathrm{PMoCu} @ \mathrm{MgCu} 2 \mathrm{O} 4$ - PVA composite as a high-performance heterogeneous nanocatalyst"; Chem. Eng. J. 333, 537-544, 2018.

[7] Zhao, H.; Baker, G. A.; Zhang, Q.; "Design rules of ionic liquids tasked for highly efficient fuel desulfurization by mild oxidative extraction"; Fuel 189, 334-339, 2017.

[8] Chen, L. J.; Li, F. T.; "Oxidative desulfurization of model gasoline over modified titanium silicalite'; Pet. Sci. Technol. 33, 196-202, 2015.

[9] Zhao, H.; Baker, G. A.; Zhang, Q.; "Design rules of ionic liquids tasked for highly efficient fuel desulfurization by mild oxidative extraction"; Fuel 189, 334-339, 2017.

[10] Bakar, W. A.; Ali, R.; Kadir, A.; Mokhtar, W. N.; "Effect of transition metal oxides catalysts on oxidative desulfurization of model diesel"; Fuel Proc. Technol. 101, 78-84, 2012.

[11] Subhan, S.; Rahman, A. U.; Yaseen, M.; Haroon, H. U.; Isha, M.; Sahibzada, M.; Tong, Z.; "Ultra-fast and highly efficient catalytic oxidative desulfurization of dibenzothiophene at ambient temperature over low Mn"; Feul, 23-56, 2012.

[12] Xun, S.; Zhu, W.; Chang, Y. H.; Zhang, Li. M.; Jiang, W.; Zheng, D. Y.; Li, H.; "Designing multifunctional SO3H-based polyoxometalate catalysts for oxidative desulfurization in acid deep eutectic solvents"; Chem. Eng. J. 288, 608-617, 2016.

[13] Li, J. j.; Xiao, H.; Tang, X. D.; Zhou, M.; "Extractive Desulfurization of Model Oil with Protic Ionic Liquids"; Ene. Fuels 30, 5411- 5418, 2016.

[14] Safa, M.; Mokhtarani, B.; Mortaheb, H. R.; "Density and viscosity of pyridinium-based ionic liquids and their binary mixtures with water at several temperatures"; Chem. Eng. Res. Des. 111, 323-331, 2016.

[15] Yuan, J.; Xiong, J.; Wang, J.; Ding, W.; Yang, L.; Zhang, M.; Zhu, W.; Li, H.; "Phosphomolybdic acid immobilized on ionic liquid-modified hexagonal boron nitride for oxidative desulfurization of fuel"; J. Porous Mater. 23, 823-831, 2016.

[16] Chandran, D.; Khalid, M.; Walvekar, R.; Mubarak, N. M.; Dharaskar, S.; Wong, W. Y.; Gupta, T. C.; Manikyam, S., Deep eutectic solvents for extraction-desulphurization: A review, Journal of Molecular Liquids, 27, 723-831, 2018.

[17] Wilfred, C. D.; Kiat, C. F.; Man, Z.; Bustam, M. A.; Mutalib, M. I. M.; Phak, C. Z.; "Extraction of dibenzothiophene from dodecane using ionic liquids"; Fuel Process. Technol 93, 85- 89, 2012.

[18] Gordon, C. M.; "New developments in catalysis using ionic liquids"; Appl. Catal. A.-Gen. 222, 101$117,2001$.

[19] Welton, T.; "Ionic liquids in catalysis"; Coord. Chem. Rev. 248, 2459-2477, 2004.

[20] Warrag, S. E.; Peters, C. J.; Kroon, M. C.; "Deep eutectic solvents for highly efficient separations in oil and gas industries"; Curr. Opin. Green Sustain. Chem. 5, 55-60, 2017.

[21] Kerton, F. M.; Marriott, R.; "Alternative Solvents for Green Chemistry"; Second edition, Royal Society of Chemistry, 2013.

[22] Zhu, W.; Wang, C.; Li, H.; Wu, P.; Xun, S.; Jiang, W.; Chen, Z.; Zhao, Z.; Li, H.; "One-pot extraction combined with metal-free photochemical aerobic oxidative desulfurization in deep eutectic solvent"; Green Chem. 17, 2464-2472, 2015.

[23] Peric, B.; Sierra, J.; Mart, E.; Cruañas, R.; Garau, M. A.; Arning, J.; Bottin-Weber, U.; Stolte, S.; "Toxicity and biodegradability of selected protic and aprotic ionic liquids"; J. Hazard. Mat. 261, 99-105, 2013.

[24] Pham, T. P. T.; Cho, C. W.; Yun, Y. S.; "Environmental fate and toxicity of ionic liquids, a review"; Water Res. 44, 352-372, 2010.

[25] Abbott, A. P.; Boothby, D.; Capper, G.; Davies, D. L.; Rasheed, R. K.; "Deep eutectic solvents formed between choline chloride and carboxylic acids: versatile alternatives to ionic liquids"; J. Am. Chem. Soc. 126, 9142-9147, 2004. 


\section{Al-Nahrain Journal of Science}

ANJS, Vol.23 (2), June, 2020, pp. 8 - 17

[26] Li, C.; Li, D.; Zou, S.; Li, Z.; Yin, J.; Wang, A.; Cui, Y.; Yao, Z.; Zhao, Q.; "Extraction desulfurization process of fuels with ammonium-based deep eutectic solvents"; Green Chem. 15, 2793-2799, 2013.

[27] Gano, Z. S.; Mjalli, F. S.; Al-Wahaibi, T.; AlWahaibi, Y.; "The Novel Application of Hydrated Metal Halide (SnCl2. 2H2O)-Based Deep Eutectic Solvent for the Extractive Desulfurization of Liquid Fuels"; Int. J. Chem. Eng. Appl. 6, 367-371, 2015.

[28] Abood, H. M. A.; Abid, H. S.; "DSC and TGA measurement of room temperature ionic liquids (RTILs) containing Ammonium Alum or Aluminium Nitrate with Amide"; Al-Nahrain J. Sci. 18 (2) 56-68, 2015.

[29] Al-Qudsi, Z. N.; Abood, H. M. A.; "The Electronic Transition Behavior Cr (III), Fe (III), Fe (II) and Ni (II), Transition Metal Cations In Ammonium AlumUrea Room Temperature Ionic Liquid"; Al-Nahrain J. Sci. 16 (3), 46 - 55, 2013.

[30] Phase, J.; Langer, B.; Schrader, V.; Bastian, E.; Jacob, J.; "Infrared spectra and force constant of urea in the gaseous"; Chem. 352, 489, 1995.

[31] Podsiadła, D.; Ryba-Romanowski, W. S.; Czupin'ski, O.; Czapla, Z.; "Chromium doped deuterated (CH3)2NH2Al(SO4)2 $\cdot 6 \mathrm{H} 2 \mathrm{O}$ crystals"; J. Molec. Struct. 555, 33-34, 2000.

[32] Isao, S.; "Infrared spectra and normal vibrations of acetamide and its analogues"; Bull. Chem. Soc. Jap. 35(8), 1962.

[33] Tang, X. D.; Zhang, Y. f.; Li, J. J.; Zhu, Y. Q.; Qing, D. Y.; Deng, Y. X.; "Deep extractive desulfurization with arenium ion deep eutectic solvents"; Ind. Eng. Chem., Res. 54, 4625-4632, 2015.
[34] Li, J. J.; Xiao, H.; Tang, X. D.; Zhou, M.; "Green carboxylic acid-based deep eutectic solvents as solvents for extractive desulfurization"; Ene. Fuels $30,5411-5418,2016$.

[35] Hadj-Kali, M. K. S.; Mulyono, H. F.; Hizaddin, I.; Wazeer, L.; El-Blidi, E.; Ali, M. A.; Hashim, I. M.; "Removal of thiophene from mixtures with $\mathrm{n}^{-}$ heptane by selective extraction using deep eutectic solvents"; Ind. Eng. Chem. Res. 55, 8415-8423, 2016.

[36] Javadli, R. De.; Klerk, A.; "Desulfurization of heavy oil"; Appl. Petrochem. Res. 1, 3-19, 2012.

[37] Li, C.; Zhang, J.; Li, Z.; Yin, J.; Cui, Y.; Liu, Y.; Yang, G.; "Extraction desulfurization of fuels with 'metal ions' based deep eutectic solvents (MDESs)"; Green Chem. 18, 3789-3795, 2016.

[38] Khezeli, T.; Daneshfar, A.; "Synthesis and application of magnetic deep eutectic solvents: Novel solvents for ultrasound assisted liquid-liquid microextraction of Thiophene"; Ultrason. Sonochem. 38, 590-597, 2017.

[39] Zaid, H. F. M.; Chong, F. K.; Mutalib, M. I. A.; "Extractive deep desulfurization of diesel using choline chloride-glycerol eutectic-based ionic liquid as a green solvent"; Fuel 192, 10-17, 2017.

[40] Tang, X. L.; Shi, L.; "Study of the adsorption reactions of thiophene on $\mathrm{Cu}$ (I)/HY-Al2O3 by Fourier transform infrared and temperatureprogrammed desorption: Adsorption, desorption, and sorbent regeneration mechanisms"; Langmuir 27, 11999-12007, 2011. 